\title{
Современные возможности антиоксиАантной терапии шафраном в офтальмологической практике: обоснование применения и потенциальная кАиническая эффективность
}

\begin{abstract}
Резюме. В обзоре рассматриваются распространенные возраст-ассоциированные заболевания глаз, патогенез которых связан с оксидативным стрессом. Шафран обладает выраженными антиоксидантными свойствами: препятствует окислению полиненасыщенных жирных кислот, предотвращает мембранодеструктивные процессы в фоторецепторах, увеличивает стабильность липидного слоя мембран. Гликозиды и каротиноид зеаксантин, содержашиеся в шафране, создают депо антиоксидантов и реактивируют истощенную антиоксидантную систему сетчатки; биофлавоноиды укрепляют стенки кровеносных сосудов, снижают проницаемость гематопаренхиматозных барьеров, стимулируют процесс биосинтеза белка, ускоряют процессы регенерации. В настоящее время проведено большое количество клинических исследований, демонстрирующих высокую эффективность и безопасность шафрана в лечении возраст-ассоциированных заболеваний глаз.
\end{abstract}

Ключевые слова: возраст-ассоциированные заболевания глаз; шафран; антиоксидантные свойства; обзор

В наше время в мире отмечается неуклонный рост зрительных нарушений и заболеваний глаз, что связано со старением населения и, соответственно, с увеличением возрастных инволюционных изменений в зрительном анализаторе. Согласно статистическим данным, представленным экспертами Всемирной организации здравоохранения, около 314 млн человек имеют различные патологии зрения, 45 млн - слепы [1]. Среди основных причин слепоты доминируют возраст-ассоциированные заболевания глаз - катаракта, возрастная макулярная дегенерация, глаукома и диабетическая ретинопатия [2].

Катаракта, по сведениям ВО3, обусловливает до 47,9 \% случаев слепоты во всем мире. В возрастной группе 50-60 лет ее выявляют у $15 \%$ населения, 7080 лет - у 26-46\%, старше 80 лет - практически у каждого [2-4].

Не меньшую опасность для зрения представляет возрастная макулярная дистрофия (ВМД), нередко заканчивающаяся инвалидностью $[5,6]$. В экономически развитых странах ВМД как причина слабовидения занимает третье место в структуре глазной патологии после катаракты и глаукомы $[7,8]$. Терминальная стадия ВМД (слепота) встречается у 1,7 \% всего населения старше 50 лет и около $18 \%$ населения старше 85 лет $[9,36]$.

В 12,3\% случаев к потере зрения приводит глаукома $[2,10]$. Как известно, частота заболевания ассоциирована с возрастом: в группе 40-45-летних людей она обнаруживается в $0,1 \%$ случаев; у 50-60-летних - в 1,5\% наблюдений; после 75 лет - более чем в $3 \%$ случаев [11]. В 4,8 \% случаев хронической слепотой сопровождается прогрессирование диабетической ретинопатии: от 5 до $20 \%$ больных сахарным диабетом теряют зрение каждые 5 лет [2, 12].

Следует отметить, что все возраст-ассоциированные заболевания глаз, приводящие к зрительным нарушениям и слепоте, значительно снижают трудоспособность пациентов, ухудшают возможности самообслуживания и качество жизни, становятся тяжелым бременем для близкого окружения. Это актуализирует

(С) «Архів офтальмологіїУкраїни» / «Архив офтальмологии Украины» / «Archive Of Ukrainian Ophthalmology» («Arhìv oftal'mologiï Ukraïni»), 2018

(c) Видавець Заславський 0.Ю. / Издатель Заславский А.Ю. / Publisher Zaslavsky 0.Yu., 2018

Для корреспонденции: Петренко Оксана Васильевна, доктор медицинских наук, Национальная медицинская академия последипломного образования имени П.Л. Шупика, ул. Дорогожицкая, 9, г. Киев, 04112, Украина; е-mail: redact@i.uа

For correspondence: Oksana Petrenko, MD, PhD, Shupyk National Medical Academy of Postgraduate Education, Dorohozhytska st., 9, Kyiv, 04112, Ukraine; e-mail: redact@i.ua 
проблему и требует поиска и разработки новых подходов к лечению и профилактике данной офтальмологической патологии.

\section{ОксиАативный (Окислительный) стресс - важное звено патогенеза возраст-ассоциированных заболеваний глаз}

В настоящее время установлено, что в патогенезе возраст-ассоциированных заболеваний глаз важную роль играет оксидативный стресс. Ткани глаза непрерывно подвергаются агрессивному воздействию синего спектра солнечного света. В результате фотоокисления образуются синглетная форма кислорода и его свободные радикалы, вызывающие такие повреждения клеток, как окисление липидов, разрушение белков и повреждение ДНК $[13,14]$. Кроме того, немаловажная роль в развитии оксидативного стресса отводится дефициту питания вследствие нарушенного всасывания, неблагоприятным экологическим условиям, курению, инфекциям и некоторым лекарственным препаратам [19].

Известно, что в норме клетки организма имеют большое число защитных механизмов в форме антиоксидантов и восстанавливающих ферментов, которые успешно защищают клетки от окислительного повреждения, вызванного свободными радикалами. И хотя окислительный стресс действует в течение всей жизни, его результаты особенно ощутимы с возрастом. Полагают, что по мере старения организма происходит истощение антиоксидантной системы защиты и ухудшение обмена веществ. Это приводит к состоянию, при котором количество свободных радикалов значительно превышает возможности защитных антиоксидантных систем и клетки становятся уязвимыми к разрушению. Особенно чувствительна к окислительному стрессу сетчатка, поскольку она нуждается в большом количестве кислорода, подвергается чрезвычайно высокому уровню воздействия света, способного инициировать выработку свободных радикалов, а мембраны клеток содержат большое количество легкоокисляемых полиненасыщенных жирных кислот $[15,16]$.

Свободные радикалы также обладают сродством к ненасыщенным жирным кислотам - главному компоненту клеточных мембран фоторецепторов. В результате такого взаимодействия в пигментном эпителии образуются и откладываются высокомолекулярные полимеры с высоким содержанием липофусцина пигмента старости. В свою очередь, это приводит к расширению зон атрофии клеток пигментного эпителия и гибели фоторецепторов [17].

При сахарном диабете центральную роль в развитии окислительного стресса играет гипергликемия. Аутоокисление глюкозы, неферментативное гликозилирование и активация метаболизма сорбита являются источниками образования свободных радикалов или активных форм кислорода при этом заболевании. В условиях нормального метаболизма они также образуются, но быстро инактивируются. В условиях дисбаланса между продукцией и инактивацией развивается оксидативный стресс. Помимо этого, длительная ги- пергликемия приводит к нарушению проницаемости капилляров, потере перицитов, образованию микроаневризм и гипоксии сетчатки [12].

Таким образом, учитывая важную роль оксидативного стресса в развитии и прогрессировании возрастассоциированных заболеваний глаз, эффективным и патогенетически обоснованным методом их профилактики и лечения является применение антиоксидантной терапии. Еще в 1992-2001 гг. в крупном исследовании Age Related Eye Disease Study (AREDS) с включением 11 центров США и 4757 пациентов в возрасте 55-88 лет с ВМД и катарактой была установлена эффективность и безопасность применения антиоксидантной терапии. Результаты AREDS показали, что ее назначение уменьшает риск прогрессирования ВМД и катаракты на 17 \% по сравнению с плацебо-контролем, при сочетании антиоксидантов и минералов - на $25 \%$ [20].

\section{Биохимический состав, антиоксиАантные и метаболические свойства шафрана, механизмы ретинопротекции}

Исследования последних лет показывают, что в лечении и профилактике возраст-ассоциированных заболеваний глаз несомненным преимуществом обладают антиоксиданты растительного происхождения [21, 22]. Это объясняется их способностью синтезировать физиологически активные соединения в доступной для усвоения форме, возможностью адаптироваться к системам транспорта через клеточную мембрану, эффективностью и высокой безопасностью, полифункциональностью, малой токсичностью, минимальными побочными эффектами, отсутствием развития лекарственной зависимости. В этом отношении особый интерес представляет биологически активная добавка шафран, разнообразие и уникальность химического состава которой обеспечивает многогранность биологического действия на метаболические и структурные системы организма.

Основу химического состава шафрана формируют такие составляющие, как каротиноиды ликопин, $\alpha-$, $\beta$ - и $\gamma$-каротин, зеаксантин; гликозиды - кроцетин, сафрональ, пикрокроцин; флавоноиды - изорамнетин, кемпферол; эфирное и жирное масло; витамины группы В (тиамин, рибофлавин); минеральные вещества - медь, калий, кальций, марганец, железо, селен, фосфор, цинк и магний [23].

Установлено, что одним из механизмов ретинопротекторного действия шафрана является реализация его антиоксидантных свойств. Шафран, как антиоксидант [27, 28], препятствует окислению полиненасыщенных жирных кислот, предотвращает мембранодеструктивные процессы в фоторецепторах и инактивацию мембраносвязанных ферментных комплексов, увеличивает стабильность липидного слоя мембран. На фоне этих процессов происходит стабилизация и других биохимических показателей в глазу. Так, в исследовании азербайджанских ученых Х.В. Бабаева и соавт. (2016) было показано, что назначение шафрана предотвращает подавление активности антиоксидантных ферментов (ка- 
талазы, супероксиддисмутазы и глутатионпероксидазы) при дистрофических процессах в сетчатке. Этому способствует и тот факт, что шафран стабилизирует окислительно-восстановительное равновесие за счет мобилизации естественных антиоксидантных систем [29].

Второй механизм ретинопротекторной активности биологически активной добавки, содержащей шафран, связывают с поддержанием баланса про- и антиоксидантных систем. Наличие в экстракте шафрана гликозидов и каротиноида зеаксантина позволяет создать депо антиоксидантов и реактивировать истощенную собственную антиоксидантную систему сетчатки. Входящие в состав шафрана $\alpha$ - и $\beta$-каротины, ликопин являются основными предшественниками витамина А, способствующими образованию в организме ретинола (основного пигмента сетчатки - родопсина и пигмента колбочек - йодопсина), что, в свою очередь, улучшает работу зрительного анализатора, запуская механизмы восприятия света. Кроме каротиноидов из группы природных полифенолов, в экстракте шафрана содержатся биофлавоноиды (изорамнетин, кемпферол), которые способствуют укреплению стенок кровеносных сосудов, снижают проницаемость гематопаренхиматозных барьеров, стимулируют процесс биосинтеза белка, ускоряют процессы регенерации [24, 25, 36].

Калий, входящий в состав шафрана, - важный компонент клеток и жидкостей организма, марганец и медь используются как кофакторы для антиоксидантного фермента супероксиддисмутазы, железо - как кофактор для ферментов цитохромоксидазы, селен и цинк защищают клеточные мембраны и предупреждают генерацию свободных радикалов, кальций и магний играют важную роль в клеточном метаболизме. Витамины группы В участвуют в проведении нервных импульсов по зрительным волокнам, входят в состав зрительного пигмента, а также участвуют в синтезе фермента, понижающего внутриглазное давление [26].

В комплексе все составляющие шафрана оказывают нормализующее и стимулирующее действие на биохимические процессы в зрительном анализаторе. Они уменьшают выраженность оксидативного стресса, нормализуют метаболические процессы, укрепляют стенки кровеносных сосудов, что, в свою очередь, приводит к восстановлению и улучшению функционального и структурного состояния глаз.

\section{Аоказательная база применения шафрана при возраст- ассоциированных заболеваниях глаз}

На сегодняшний день применение шафрана при возраст-ассоциированных заболеваниях глаз имеет достаточную доказательную базу, которая демонстрирует эффективность и безопасность его применения в лечении данных патологий.

Так, в исследовании, проведенном B. Falsini et al. (2010), изучалось влияние биологически активной добавки шафран на чувствительность сетчатки к свету у пациентов с ранней возрастной макулярной дистрофией. В нем приняли участие 25 пациентов, которые случайным образом были распределены на 2 группы. Первая группа (n = 13) получала шафран по 20 мг/сут ежедневно, вторая $(\mathrm{n}=12)$ - плацебо на протяжении 6 месяцев. Оценка результатов лечения проводилась через 3 и 6 месяцев по результатам электроретинограммы [30].

Результаты исследования продемонстрировали повышение электрической активности и амплитуды волн, свидетельствующее об улучшении чувствительности сетчатки к свету у пациентов, принимающих шафран, в сравнении как с исходным уровнем, так и с плацебо. Это позволило авторам сделать вывод о целесообразности назначения биологически активной добавки, содержащей шафран, больным, страдающим макулярной дистрофией сетчатки, в целях улучшения функционального состояния сетчатки и прогноза заболевания.

B исследовании итальянских ученых D. Marangoni et al. (2013) также изучалось влияние биологически активной добавки, содержащей шафран, на светочувствительность сетчатки при возрастной макулярной дистрофии. На протяжении 6-12 месяцев 33 пациента с данным заболеванием глаз получали 20 мг/сут шафрана ежедневно [31].

Для оценки эффективности сравнивалась макулярная фокальная электроретинограмма до начала исследования и после лечения каждые 3 месяца. В ходе исследования было обнаружено, что применение шафрана обеспечивает улучшение светочувствительной функции сетчатки: уже через 3 месяца его ежедневного приема отмечалось повышение амплитуды волн на электроретинограмме, причем эти показатели были стабильны на протяжении всего периода наблюдения.

Аналогичное исследование было проведено M. Piccardi et al. (2012) с участием 29 пациентов в возрасте 55-85 лет с ВМД, на протяжении 14 месяцев получающих биологически активную добавку, содержащую шафран, в дозе 20 мг/сут. Контроль эффективности осуществлялся каждые 3 месяца с помощью электроретинографического исследования светочувствительности сетчатки и определения остроты зрения [33].

Результаты исследования показали эффективность шафрана уже через 3 месяца приема: отмечалось улучшение светочувствительности на 0,3 логарифмической единицы по сравнению с исходными данными, а остроты зрения по таблице Снеллена - на 0,2 единицы.

Австралийскими учеными D. Stone et al. (2013) было проведено двойное слепое исследование с контрольной группой, в котором изучалась эффективность и безопасность воздействия биологической добавки, содержащей шафран, на остроту зрения у пациентов с возрастной макулярной дистрофией. Все пациенты были разделены на 2 группы: первая получала шафран по 20 мг/сут, вторая - плацебо на протяжении 3 месяцев. Через 3 месяца, не сообщая пациентам, группы меняли местами. Поэтому каждый пациент, принявший участие в исследовании, принимал и шафран, и плацебо [32].

Пациенты, получавшие шафран в первые 3 месяца, сообщили о значительном улучшении зрения, которое отмечалось уже на 2-й неделе его приема и сохранялось на протяжении 3 месяцев наблюдения. Пациенты, получавшие плацебо, не отметили изменений со стороны зрения. После того как группы поменяли местами, пациенты, по- 
лучающие плацебо, сообщили, что их зрение вновь ухудшилось, тогда как те, которые стали получать шафран, отметили значительное улучшение, что подтверждалось результатами макулярной ретинографии. При этом авторы исследования отмечали, что шафран - абсолютно безопасный нутрицевтик, который хорошо переносится пациентами и не вызывает побочных эффектов.

В пилотном исследовании М. Bonyadi et al. (2014) изучалось влияние биологически активной добавки, содержашей шафран, на внутриглазное давление у пациентов, страдающих открытоугольной глаукомой. В нем приняли участие 34 пациента с данной патологией, рандомизированных на 2 равные группы, которые на протяжении месяца в дополнение к лечению глазными каплями тимолол и дорзоламид получали шафран в дозе 20 мг/сут либо плацебо.

После 4 недель терапии внутриглазное давление в группе пациентов, получающих шафран, составило $10,6 \pm 3,0$ мм рт.ст. против $13,8 \pm 2,2$ мм рт.ст. в группе контроля, что позволило авторам сделать вывод об эффективности шафрана в терапии глаукомы [34].

\section{ВывоAЫ}

1. На сегодняшний день отмечается рост распространенности возраст-ассоциированной патологии глаз, что объясняется старением населения во всем мире. Катаракта, глаукома, возрастная макулярная дистрофия сетчатки, диабетическая ретинопатия - широко распространенные заболевания, нередко приводящие к слепоте.

2. В патогенезе офтальмологической патологии, связанной с возрастом, важную роль играет оксидативный стресс, при котором образуются свободные радикалы, вызывающие повреждение клеток. Немаловажная роль принадлежит истощению собственных антиоксидантных систем организма, вызванному старением.

3. Шафран состоит из каротиноидов, флавоноидов, гликозидов, витаминов и минералов, обладающих антиоксидантными и метаболическими свойствами, необходимыми для профилактики и лечения возрастассоциированной патологии глаз.

4. Шафран, как антиоксидант, препятствует окислению полиненасыщенных жирных кислот, предотвращает мембранодеструктивные процессы в фоторецепторах и инактивацию мембраносвязанных ферментных комплексов, увеличивает стабильность липидного слоя мембран. Также он поддерживает баланс про- и антиоксидантных систем, создает депо антиоксидантов и реактивирует истощенную антиоксидантную систему сетчатки.

5. Биологически активная добавка, содержащая шафран, имеет достаточную доказательную базу, демонстрирующую эффективность и безопасность применения при возраст-ассоциированных заболеваниях глаз.

6. С учетом мощных антиоксидантных свойств шафрана его применение может быть рекомендовано для лечения и профилактики не только возраст-ассоциированных заболеваний глаз, но и другой офтальмологической патологии, в патогенезе которой ключевая роль принадлежит оксидативному стрессу.
На сегодняшний день на фармацевтическом рынке Украины появился препарат компании «Фармаплант Украина» МакулоВит, активным компонентом которого является шафран, что открывает новые перспективы в лечении заболеваний органа зрения.

Конфликт интересов. Не заявлен.

\section{Список ^итературы}

1. Нарушения зрения и слепота // Информационный бюллетень ВОЗ. - 2009. - № 282. (http://www.who.int/mediacentre/ factsheets/fs282/ru/index.html).

2. Проблемы слепоты и слабовидения. КБУ РО «КБ им. H.A. Семашко». (http://old.xn--62-6kctOakqtOe.xn--plai/novosti/ problemy-slepoty-i-slabovidenia).

3. Шильников Л.В. Глазные болезни: конспект лекций. https://med.wikireading.ru/7016.

4. Катаракта. http://www.krasotaimedicina.ru/diseases/ophthalmology/cataract.

5. Klein R., Klein B.E.K., Jensen S.C., Meuer S.M. The five-year incidence and progression of age-related maculopathy. The Beaver Dam Eye Study // Ophthalmology. - 1997. - Vol. 104. - P. 7-21.

6. Williams R.A., Brady B.L., Thomas R.J. The psychosocial impact of macular degeneration // Arch. Ophthalmol. - 1998. 116 (4). - P. 514-520.

7. Klein R., Klein B.E.K., Lee K.E. et al. Changes in visual acuity in a population over a 10-year period. The Beaver Dam Study // Ophthalmology. - 2001. - Vol. 108. - P. 1757-1766.

8. Klein R., Klein B.E.K. et al. The association of Cataract and Cataract Surgery with the long-term incidence of age-related maculopathy // Arch. Ophthalmol. - 2002. - Vol. 102. - P. 1551-1557.

9. Klein R., Klein B.E.K., Tomany S.C. et al. Ten-year incidence and progression of age-related maculopathy // Ophthalmology. 2002. - Vol. 109. - P. 1767-1778.

10. Глаукома вторичная вследствие других болезней глаз // РЦРЗ, клинические протоколы МЗ РК. - 2013.

11. Глаукома: классификация, ее стадии, формы, виды. https://glazaexpert.ru/glaukoma/glaukoma-klassifikatsiya.

12. Ищенко И.А., Миленькая Т.М. Эффективность применения антиоксидантов в лечении диабетической ретинопатии // РМЖ: Клиническая офтальмология. - 2007. - 8(3). - С. 97-101.

13. Зенков Н.К., Ланкин В.З., Меньщикова Е.Б. Окислительный стресс. - М., 2001. - 315 c.

14. Кравчук Е.А. Роль свободнорадикального окисления в патогенезе заболеваний глаз // Вестник офтальмологии. 2004. - T. 120, № 5. - C. 48-51.

15. Старостин А.В., Островский М.А., Федорович И.Б., Львов К.М. ЭПР-исследование светоиндуцированной агрегации родопсина в фоторецепторной мембране // Биофизика. 1987. - T. 32. - C. 624-627.

16. Liles M.R., Newsome D.A., Oliver P.D. Antioxidant enzymes in the aging human retinal pigment epithelium // Archives of Ophthalmology. - 1991. - Vol. 109, № 9. - P. 503-512.

17. Марченко Л.Н. Патогенез и лечение центральной инволюционной хориоретинальной дистрофии // Медицинские новости. - 2001. - № 5- C. 3-11.

18. Маркова Е.Ю., Матвеев А.В., Кузнецова Ю.Д., Ковалевская М.А., Дергачева Л.И. Современная антиоксидантная терапия в детской офтальмологии // Эффективная фармакотерапия. Педиатрия. - 2011. - № 4. 
19. Панков О.П. Антиоксиданты при лечении глазных заболеваний. https://librolife.ru/g4342760.

20. Минералы и антиоксиданты в лечении возрастной макулярной дегенерации // Клиническая офтальмология. 2017. - № 1 .

21. Hosseinzadeh H., Zeall T., Sadeghi A. The effect of saffron, Crocus sativus stigma, extract and its constituents safranal and crocin on sexual behaviors in normal male rats // Phytomedicine. - 2008. V. 15. - № 6-7. - P. 491-495.

22. Masunaga N., Chikaraishi Y., Shimazawa M. et al. Vaccinium myrtillus (Bilberry) extracts reduce angiogenesis in vitro and in vivo // Evidence-Based Complementary and Alternative Medicine. - 2010. - № 1. - P. 47-56.

23. Шафран. https://www.neboleem.net/shafran.php.

24. Налобнова Ю.В., Егоров Е.А., Ставицкая Т.В. Влияние препарата Миртикам на функциональное состояние сетчат$\kappa и$ больных с центральной инволюционной хориоретинальной дистрофией // Клиническая офтальмология. - 2003. - T. 4, № 1. - C. 29-31.

25. Каражаева М.И., Саксонова Е.О., Клебанов Г.И. и др. Флавоноидные антиоксиданты в комплексном лечении больных с дистрофической отслойкой сетчатки // Русский медицинский журнал. - 2004. - T. 5, № 1. - C. 41-44.

26. Шафран. http://lifebio.wiki.

27. Assimopoulou A., Sinakos Z., Papageorgiou V.P. Radical scavenging activity of Crocus sativus L. extract and its bioactive constituents // Phytother. Res. - 2005. - V. 11, № 19. - P. 997-1000.

28. Verma S.K., Bordia A. Antioxidant property of saffron in man // Indian J. Med. Sci. - 1998. - V. 5, № 52. - P. 205-207.

29. Бабаев Х.Ф., Шукюрова П.А. Экспериментальное исследование действия шафрана посевного (Crocus sativus L.) при токсическом поражении сетчатки. - Институт физиологии им. А.И. Караева НАН Азербайджана, 2016.
30. Falsini B., Piccardi M., Minnella A., Savastano C., Capoluongo E., Fadda A., Balestrazzi E., Maccarone R., Bisti S. Influence of saffron supplementation on retinal flicker sensitivity in early age-related macular degeneration // Send to Invest Ophthalmol. Vis. Sci. 2010. - 51 (12). - P. 6118-24. doi: 10.1167/iovs.09-4995. Epub 2010 Aug 4.( https://www.ncbi.nlm.nih.gov/pubmed/20688744/)

31. Marangoni D., Falsini B. et al. Functional effect of Saffron supplementation and risk genotypes in early age-related macular degeneration: a preliminary report // J. Transl. Med. - 2013. - 11. 228. https://www.ncbi.nlm.nih.gov/pmc/articles/PMC3850693/.

32. Шафран лечит макулярную дегенерацию. http://www.novostioede.ru/article/shafran_lechit_makulyarnuyu_degeneratsiyu/.

33. Piccardi M. et al. A Longitudinal Follow-Up Study of Saffron Supplementation in Early Age-Related Macular Degeneration: Sustained Benefits to Central Retinal Function // Evidence-Based Complementary and Alternative Medicine Volume. - 2012, Article ID 429124, 9 pages http://dx.doi.org/10.1155/2012/429124.

34. Bonyadi $M$. The ocular hypotensive effect of saffron extract in primary open angle glaucoma: a pilot study // BMC Complementary and Alternative Medicine The official journal of the International Society for Complementary Medicine Research (ISCMR). - 2014. 14. - 399. https://bmccomplementalternmed.biomedcentral.com/ articles/10.1186/1472-6882-14-399\#Sec2.

35. Киселева Т.Н. Роль антоцианозидов в коррекции нарушений микроциркуляции и гемодинамики глаза при офтальмопатологии // Российский офтальмологический журнал. - 2013. № 1. - С. 8 - 10 .

36. Киселева Т.Н., Полунин Г.С., Будзинская М.В. и др. Современные подходы к лечению и профилактике возрастной макулярной дегенерации // Клиническая офтальмология. 2007. - № 2. - C. 78-82.

Получено 05.11.2018

Петренко О.В., Яковець А.І.

Національна меАична академія післядипломної освіти імені П.А. Шупика, м. Київ, Україна

\section{Сучасні можливості антиоксиАантної терапії шафраном в офтальмологічній практиці: об'рунтування застосування та потенційна кАінічна ефективність}

Резюме. В огляді розглядаються поширені вік-асоційовані захворювання очей, патогенез яких пов'язаний з оксидативним стресом. Шафран має виражені антиоксидантні властивості: запобігає окисленню поліненасичених жирних кислот, запобігає мембранодеструктивним процесам у фоторецепторах, збільшує стабільність ліпідного шару мембран. Глікозиди та каротиноїд зеаксантин, що містяться в шафрані, створюють депо антиоксидантів і реактивують виснажену антиоксидантну сис- тему сітківки; біофлавоноїди зміцнюють стінки кровоносних судин, знижують проникність гематопаренхіматозних бар'єрів, стимулюють процес біосинтезу білка, прискорюють процеси регенерації. На сьогодні проведено велику кількість клінічних досліджень, що демонструють високу ефективність і безпеку шафрану в лікуванні вік-асоційованих захворювань очей.

Ключові слова: вік-асоційовані захворювання очей; шафран; антиоксидантні властивості; огляд

O.V. Petrenko, A.I. Yakovets

Shupyk National Medical Academy of Postgraduate Education, Kyiv, Ukraine

\section{Modern possibilities of antioxidant therapy with saffron in ophthalmic practice:} the rationale for the use and potential clinical efficacy

Summary. The review examines common age-related eye diseases, the pathogenesis of which is associated with oxidative stress. Saffron has pronounced antioxidant properties: prevents the oxidation of polyunsaturated fatty acids, prevents membranedestructive processes in photoreceptors, increases the stability of the lipid layer of membranes. The glycosides and zeaxanthin carotenoid contained in saffron create a depot of antioxidants and reactivate depleted antioxidant system of the retina; bioflavonoids strengthen the walls of blood vessels, reduce the permeability of hemato-parenchymal barriers, stimulate the process of protein biosynthesis, accelerate regeneration processes. Currently, a large number of clinical studies have been conducted that demonstrate the high efficacy and safety of saffron in the treatment of ageassociated eye diseases.

Keywords: age-associated eye diseases; saffron; antioxidant properties; overview 